\title{
Ação do equipamento Bulbox - triturador de lâmpadas - no processo mitigatório dos impactos do mercúrio (HG) no meio ambiente
}

Este estudo examina a ação do equipamento Bulbox (triturador de lâmpadas) na descontaminação correta de lâmpadas fluorescentes (LF). Notadamente são processos condizentes com a Política Nacional de Resíduos Sólidos (PNRS), aprovado pela Lei $n^{\circ} 12.305$, de 02 de agosto de 2010. Tem como objetivo investigar os ganhos que a saúde humana e o meio ambiente recebem com a mitigação da exposição do mercúrio (Hg) e explicitar os benefícios da destinação final adequada de lâmpadas fluorescentes. Foram utilizados na metodologia critérios de abordagens qualitativa evidenciando instrumentos de coleta de dados voltados para o levantamento bibliográfico, documental e entrevista. Os resultados mostraram que os fatores bióticos e abióticos obtiveram ganhos significativos com a captação correta do mercúrio através do equipamento Bulbox, como também no reaproveitamento do vidro, alumínio, cobre e latão logrando desta forma resultados significativos na preservação do bem-estar dos diversos ecossistemas.

Palavras-chave: Lâmpadas Fluorescentes; Reciclagem; Políticas Ambientais no Brasil; Mercúrio, Indústria e Descontaminação.

\section{Action of the Bulbox device - lamps crusher - in the migratory impact of mercury(HG) to the environment}

\begin{abstract}
This study examines the action of the Bulbox device in the correct decontamination of fluorescent light bulbs. Notably these processes are consistent with the National Policy of Solid Residuals(PNRS), approved by the law $\mathrm{n}^{\circ} 12.305$, on August $2 \mathrm{nd} 2010$. It has the goal of investigating the benefits that the human health and the environment receive with the mitigation of mercury $(\mathrm{Hg})$ exposure and explain the benefits of the adequate final treatment of fluorescent light bulbs. In the methodology were used qualitative research criterias stressing the use of data gathering devices as a means to the bibliographic survey, documentation and interview. The results show that the biotoxic factors and abiotics had meaningful gains with the correct gathering of mercury by the Bulbox device, as the reuse of glass, aluminium, copper and brass bringing this way meaningful results in the wellness preservation of several ecosystems.

Keywords: Fluorescent light bulbs; Recycling; Environmental Policies in Brazil; Mercury, Industry and Descontamination.
\end{abstract}

\section{Topic: Engenharia Sanitária}

Reviewed anonymously in the process of blind peer.

Taumaturgo Bonfim Santos

Universidade de Pernambuco, Brasil

http://lattes.cnpq.br/3187611920148377

taumaturgobonfim@yahoo.com.br

Ivo Vasconcelos Pedrosa

Universidade de Pernambuco, Brasil

http://lattes.cnpq.br/3801922085371764

ivo.pedrosa@upe.br

Andrea Karla Pereira da Silva

Universidade Federal de Pernambuco, Brasil

http://lattes.cnpq.br/1375568180577579

andrea.silva@upe.br
Received: 10/03/2016

Approved: 15/08/2016

\section{Referencing this:}

SANTOS, T. B.; PEDROSA, I. V.. Ação do equipamento Bulbox triturador de lâmpadas - no processo mitigatório dos impactos do mercúrio (HG) no meio ambiente. Revista Ibero-Americana de Ciências Ambientais, v.7, n.3, p.111-124, 2016. DOI: http://doi.org/10.6008/SPC2179-6858.2016.003.0010 


\section{INTRODUÇÃO}

Hodiernamente vislumbram-se de forma positiva diversas ações ambientais corporativas, pois comumente a busca de boas práticas ambientais como também a necessidade de cumprimento das normas que integram as políticas públicas tem motivado nos setores industriais a correta gestão ambiental. Um aspecto dessa gestão é a destinação de resíduos de forma adequada, seja pelos imperativos da coerção de tais políticas, que impõem responsabilidade civil, administrativa e criminal decorrentes de qualquer dano am biental (GUSMÃO; DE MARTINI, 2009), seja pelos processos consciências da harmonia planetária (GUTIÉRREZ, 2013).

No entanto, aprofundando-se o foco desses novos intentos observam-se comumente posicionamentos paradoxais no tocante aos interesses principais das empresas em detrimento do respeito aos recursos naturais, pois se verificam altos índices de impactos provocados pelos resíduos perigosos industriais à saúde humana, ao solo, mares e rios, e principalmente, à exposição destes no ar (BARROS et al., 2000). Perante tal posicionamento constata-se que, apesar de existir discussão nos meios acadêmicos e corporativos, receia-se que sejam conceitos ainda pautados em procedimentos "míopes" concernentes ao desenvolvimento sustentável (CAPRA, 2006).

Urge a necessidade de as indústrias frisarem importância ao gerenciamento correto de resíduos sólidos para motivarem bem-estar ao meio ambiente (PNRS, 2010), tornando-se um dos facilitadores das relações de equilíbrio social, ambiental e econômico (RATTNER, 1999), pois a destinação correta de resíduos industriais está alicerçada aos preceitos do desenvolvimento sustentável (RIBEIRO; MORELLI, 2009). Qualquer dano ambiental causado por geradores e corresponsáveis de resíduos perigosos, os mesmos deverão arcar com multas indenizatórias e procedimentos corretivos das áreas contaminadas através de empresas que prestam serviços no tocante a soluções ambientais devidamente legalizados (GUSM ÃO; DE MARTINI, 2009).

Diante desse contexto, explicita-se que em âmbito global um perigoso agente transita entre os resíduos gerados pela indústria e se encontra nas lâmpadas de natureza fluorescentes. Esse resíduo é o mercúrio, metal pesado extremamente agressivo à saúde humana, à fauna e à flora (TOMAZELLI, 2003). Descrições explicitadas em dicionário técnico mensuram que os metais pesados são caracterizados por elementos químicos com densidade acima de $4 \mathrm{~g} / \mathrm{cm}^{3}$ ou $5 \mathrm{~g} / \mathrm{cm}^{3}$, porém os "ecotoxicologistas" interpretam o termo metal pesado como todo agente que transgrida as normalidades do meio ambiente, provocando fatores danosos à harmonia cíclica dos sistemas (PGIRPBL, 2009; WOLF \& CONCEIÇÃO, 2003).

O mercúrio utilizado em algumas lâmpadas conduz uma descarga elétrica para ocorrer à luminosidade do ambiente com o estímulo de um composto fosfórico ou gasoso (FUNDACENTRO, 2013). As lâmpadas que contêm mercúrio são: as lâmpadas de descargas em gás ou vapor de alta pressão que se subdividem em vapor de mercúrio, luz mista, vapor de sódio de alta pressão, vapor de mercúrio de iodetos metálicos; e das lâmpadas de descargas em gás ou vapor de baixa pressão que se subdividem em: vapor de sódio de baixa pressão, lâmpadas fluorescentes (vapor de mercúrio de baixa pressão) e lâmpadas 
fluorescentes (compacta). Mais precisamente iremos nos deter na "LF" de vapor de mercúrio de baixa pressão que são as mais utilizadas na indústria (PROCEL, 2002).

0 método da logística reversa de lâmpadas fluorescentes tem como intuito precípuo a descontaminação de lâmpadas fluorescentes já que um resíduo perigoso, sendo utilizado pelas organizações através do gerenciamento de resíduos sólidos por motivos ambientais e coercitivos. Concernente aos fabricantes, distribuidores, im portadores, exportadores e consumidores finais é plausível a responsabilidade de forma direta ou corresponsabilidade pelas lâmpadas comercializadas ou utilizadas do início ao fim do ciclo de vida do produto (PNMA, 1981; PNRS, 2010).

0 equipamento de trituração de lâmpadas florescentes é utilizado para execução do processo de descontaminações da "LF" utilizando o método de moagem simples, sendo um desses maquinários conhecido como Bulbox - equipamento triturador e compactador de lâmpadas fluorescentes.

Diante de comprovada importância desta retórica, rege-se como objetivo da pesquisa adotada a mensuração dos reais resultados de preservação dos recursos naturais através dos procedimentos empresariais e domésticos que incitam o encaminhamento das lâmpadas fluorescentes geradas nos processos fabris para empresas responsáveis pela captação desses materiais inservíveis e perigosos para execução da descontaminação, fomentando como consequência a mitigação dos efeitos do mercúrio e seus derivados no meio ambiente.

\section{REVISÃO TEÓRICA}

O mercúrio é um metal líquido de coloração branco prateado, não tem cheiro e é extremamente ágil no processo de volatilização (FISPQ, 2009). Constitui na atualidade um dos metais mais pesquisados e, diante de comprovações com embasamento científico, constata-se que os danos causados por ele são passíveis de imperiosas preocupações para a sociedade e, no caso industrial principalmente, para os ambientes ocupacionais (WHO, 1991).

Tem características tóxicas com propriedades biológicas acumulativas, ou seja, que se perpetua em caráter de acumulação ao longo da cadeia alimentar, além de ser de natureza persistente entrando constantemente em rotinas cíclicas, provocando variações contínuas no meio ambiente (PAWLOWSKI, 2011; RODRIGUES et al., 2010; UNEP, 2002).

Em âmbito industrial a exposição ao mercúrio e suas variações pode afetar os colaboradores por inalação de seus vapores ou por contato cutâneo com o ar contaminado (WHO, 2003), podendo desencadear intoxicações crônicas de âmbito neuropsicológico (cefaleia, cãibra, parestesia, tremor, tontura, fraqueza muscular, esquecimento e dificuldade de concentração), problemas neurológicos (irritabilidade, nervosismo, depressão e insônia) (GLINA et al., 1997), como também alterações no sistema auditivo (LIMA et al., 2009). Portanto, configura-se, a partir do conhecimento científico, que este elemento metálico, juntamente com seus derivados, é altamente tóxico para a sociedade e seus ecossistemas, sendo volátil à temperatura ambiente e ágil a altas temperaturas (MMA, 2015). Infelizmente a poluição pelo mercúrio se tornou globalizada e notadamente um perigo a ser remediado urgentemente. 
Doses elevadas podem ser fatais para o ser humano, e mesmo doses relativamente baixas podem ter efeitos nocivos no desenvolvimento neurológico, no sistema cardiovascular, imunológico e reprodutivo (FARIAS et al., 2008). Do século passado aos dias atuais diversos níveis de contaminação se efetivaram por conta desse metal pesado. Cenários desastrosos ocorreram - por exemplo - nas cidades japonesas Minamata e Niiagata, quando empresa, de trato fabril do composto acetaldeído, despejava resíduos de mercúrio nos rios contaminando a vida aquática da região (ALMEIDA, 2002; CETEM, 2006). Em três décadas 27 toneladas de compostos de mercúrio foram colocadas irregularmente nos sedimentos da baía japonesa por essa corporação (ALMEIDA, 2002).

Tais compostos foram ingeridos primeiramente por bactérias e posteriormente transferidos de maneira muito mais intensa na cadeia alimentar pelos efeitos da biomagnificação a outros seres vivos e como consequência centenas de pessoas morreram por ingestão de peixes contaminados (CRAVO et al., 2008). É um poluente orgânico persistente (POP); sendo assim, se dissemina desastrosamente chegando aos peixes e finalmente a outros animais e seres humanos de forma muito mais potencializada, pois foi observado que à medida que um agente é contaminado pelo mercúrio em um nível inferior na cadeia alimentar seu predador apresentará os níveis aumentados desse metal (BOENING, 2000; NEBEL et al., 2000); (SIQUEIRA et al., 2012).

O metilmercúrio (MeHg) se caracteriza como a variação mais tóxica do mercúrio. Grande parte da população tem um pequeno percentual de mercúrio nos tecidos; e, estima-se que a quantidade de MeHg é de alto risco para a saúde humana, pois convém observar que ele é absorvido de maneira muito intensa pelo sistema gastrointestinal permeando as barreiras placentária e hematoencefálica (BHE) que é uma estrutura de permeabilidade que seleciona e protege o sistema nervoso central de substâncias tóxicas provindas do sangue (CETESB, 2012; FIRJAM, 2000). Anos à frente do desastre de Minamata e Niiagata os hospitais recebiam simultaneamente pessoas da região com sintomas similares, dentre eles: problemas no sistema nervoso, atrofia muscular nos membros, dificuldade visual e em alguns casos sintomas fatais; justamente por isso ficou conhecida como a temível doença de Minamata (CRAVO et al., 2008).

Diversas são as estruturas de iluminação (lâmpadas fluorescentes) nas indústrias e na sociedade em geral que contêm níveis de mercúrio, que variam o percentual de acordo com a lâmpada específica. É classificada como resíduo perigoso, Classe I, sob o código F044, pela Norma ABNT 10.004/04. Na norma explicitada ocorre a classificação dos resíduos no tocante aos seus riscos potenciais ao meio ambiente e à saúde pública, informando aqueles que devem ter manuseio e destinação correta (ABNT, 2004).

Em sua constituição física existe um tubo de descarga longo, com um elétrodo nas extremidades. $\mathrm{O}$ tubo é preenchido com gás inerte o qual arranca com facilidade e controla a descarga, contém pequena deposição de mercúrio, com o objetivo de emitir radiação ultravioleta quando excitado (APLIQUIM, 2010). As "LF", por emitirem vapor de mercúrio se quebradas, irão liberá-lo, sendo possivelmente absorvido por quem as manipulou (SANCHES, 2008).

As indústrias são orientadas a destinar corretamente as lâmpadas que contêm mercúrio de forma que, ao serem abordadas pelos órgãos ambientais, tenham em mãos os certificados de destinação final atestado por empresas licenciadas. Para tanto é imprescindível que o descarte seja realizado corretamente 
(PGIRPBL, 2009). As "LF" são resíduos que por serem perigosos necessitam de cuidados redobrados, evidenciando-se o gerenciamento nas centrais de resíduos da indústria para mitigar os impactos ao meio ambiente, corroborando com o devido manuseio, acondicionamento e principalmente destinação final correta (DURÃO et al., 2008; SANCHES, 2008).

É interessante também explicitar que resíduos industriais são tratados pelas políticas públicas, possuindo o Brasil normas específicas (PNRS, 2010; PNMA, 1981). O artigo 225 da Constituição Federal demonstra a importância devida à proteção do meio ambiente especificada na Lei no 6.938 , de 31 de agosto de 1981. A Lei no 6.803 de 02 de julho de 1980, estabelece especificidades relativas às diretrizes básicas no tocante ao zoneamento industrial em áreas críticas de poluição; como também as Resoluções de números 257/263 e 258 do CONAMA (Conselho Nacional do Meio Ambiente), que dispõem sobre as possibilidades de danos causados por pilhas, baterias e pneumáticos. Infelizmente quanto às embalagens de óleo lubrificante, às lâmpadas fluorescentes e aos resíduos eletroeletrônicos, não há, no momento, regulamentação; porém a Política Nacional de Resíduos Sólidos aborda a obrigação dos geradores diretos e indiretos programarem a Logística Reversa (LR) como agente mitigador de impactos ambientais.

Segundo a PNRS (2010), são requeridas no art. 33, algumas ações:

São obrigados a estruturar e implementar sistemas de logística reversa, mediante retorno dos produtos após o uso pelo consumidor, de forma independente do serviço público de limpeza urbana e de manejo dos resíduos sólidos, os fabricantes, importadores, distribuidores e comerciantes de:

I - agrotóxicos, seus resíduos e embalagens, assim como outros produtos cuja embalagem, após o uso, constitua resíduo perigoso, observadas as regras de gerenciamento de resíduos perigosos previstas em lei ou regulamento, em normas estabelecidas pelos órgãos do Sisnama, do SNVS e do Suasa, ou em normas técnicas;

II - pilhas e baterias;

III - pneus;

IV - óleos lubrificantes, seus resíduos e embalagens;

V - Lâmpadas fluorescentes, de vapor de sódio e mercúrio e de luz mista.

A Política Nacional do Meio Ambiente (PNMA, 1981) instituiu alguns princípios que demonstram importância substancial na racionalização de critérios para uso do solo, da água e do ar; nos atos de planejar e fiscalizar os recursos naturais; como também no controle na demarcação de zoneamento das atividades poluidoras. Para preservar a eficiência e eficácia desses princípios, instituiu como instrumento devido, o licenciamento ambiental. Em âmbito estadual, diversos órgãos ambientais, em consonância com a (CF 88; PNMA, 1981; PNRS, 2010), determina a obrigatoriedade das empresas que executam a descontaminação das lâmpadas fluorescentes de autorização prévia em sua L.O (Licença de Operação) para realizarem acondicionamento, transporte e destinação final desses rejeitos perigosos como é o caso dos produtos constituídos de mercúrio (PERNAMBUCO, 2002, 2010; RIO GRANDE DO SUL, 1998; SÃO PAULO, 2006).

Uma das tecnologias utilizadas hodiernamente é o processo de moagem simples que operacionalmente efetua a quebra das lâmpadas retendo compostos perigosos e tornando o material pesado, reciclável. Um equipamento de moagem simples foi desenvolvido pela Air Cycle Corp., dos Estados Unidos, e é conhecido mundialmente como Bulb Eater ("comedor de lâmpadas" ou "papa lâmpadas"), 
semelhante a este veicula-se no mercado atual o equipamento Bulbox - triturador e compactador de lâmpadas fluorescentes que "foi desenvolvido e aperfeiçoado a partir de um antigo projeto Dinamarquês" (BULBOX, 2007).

Comumente, empresas que consumem lâmpadas fluorescentes ou fabricantes das mesmas, estão sendo obrigadas pelas leis ambientais vigentes a descontaminar lâmpadas com teor de mercúrio, transformando-as de Resíduos Perigosos (Classe I) para não perigosos (Classe II), como também reaproveitando no processo de reciclagem o vidro, alumínio, cobre e latão (RECILUX, 2016).

A importância da destinação final correta das lâmpadas fluorescentes, através do equipamento Bulbox está alicerçada em um conjunto de fatores que fomentam ganhos ambientais através da mitigação dos efeitos negativos, na natureza, do mercúrio e seus derivados na forma orgânica como o metilmercúrio $\left(\mathrm{CH}_{3} \mathrm{Hg}\right)$ e o dimetilmercúrio $\left(\left(\mathrm{CH}_{3}\right)_{2} \mathrm{Hg}\right)$.

\section{METODOLOGIA}

Com o objetivo de verificar a eficiência do equipamento de descontaminação de lâmpadas para efetivação da mitigação de impactos ambientais oriundos do mercúrio, o estudo em análise se fundamentou através de uma pesquisa de abordagem qualitativa, pois a intenção é produzir conteúdo informacionais de maneira aprofundada com caráter ilustrativo, estimulando o fomento de novas informações nos cenários produtivos acadêmicos (DESLAURIERS, 1991).

A construção de análise obteve com foco primordial os processos, com base na análise dos dados em sua linha temporal não requerendo a necessidade inicial do uso de procedimentos metodológicos estatísticos; e, finalmente, obtemperou a preocupação de âmbito maior da interpretação fenomenológica e a visualização de resultados.

\section{Unidade de Análise}

O estudo em questão foi realizado junto à Recilux - Reciclagem de Lâmpadas LTDA ${ }^{1}$, empresa do segmento de soluções ambientais atuante desde 2008 na descontaminação e trituração de todos os tipos de lâmpadas fluorescentes utilizando o Sistema Bulbox. Em Canoas, no bairro industrial São Luiz, está localizada a unidade de armazenamento, onde são encaminhados todos os materiais recolhidos nos estabelecimentos que contratam o serviço em todo o Rio Grande do Sul. O restante do processo, que consiste na descontaminação, trituração das lâmpadas e separação dos componentes, é feito na unidade de São João do Sul (SC). A Recilux é uma empresa com certificado de regularidade pelo Instituto Brasileiro de Meio Ambiente e dos Recursos Naturais (IBAMA) nas regiões de Santa Catarina e Rio Grande do Sul com também autorização de transporte de resíduos pelo órgão estadual de nome Fundação Estadual de Meio Ambiente (FEPAM). O certificado de regularidade do (IBAMA) na região de Santa Catarina foi expedido sob registro de $n^{\circ} 6157433$ e na região do Rio Grande do Sul sob registro de n 4010561 e em âmbito estadual conferido a Autorização

\footnotetext{
${ }^{1}$ A empresa estudada notificou autorização para divulgação de logotipo, logomarca e dados cedidos. 
Manifesto de Transporte de Resíduos (AUTMTR) sob n 00359/2010-DL e Licença de Operação (OP) sob n 04258/2014-DL.

\section{Procedimento para Coleta de Dados}

Em relação aos instrumentos de coleta de dados foi de vital importância à utilização de levantamento documental, bibliográfico e entrevista. A abordagem documental científica foi aplicada dentro dos critérios de documentos primários e secundários (MEDEIROS, 2014). Foi cedido pelo corpo diretivo da empresa Recilux o relatório da análise físico-química dos materiais decompostos pós-descontaminação das lâmpadas que foi analisado pelo laboratório TECLAB - tecnologia em análises ambientais, empresa especializada em análise ambiental com certificação ISO 9001:2008; ISO 14001:2004 e ISO 17025:2005. Esta análise foi realizada no mês de agosto de 2014. Os documentos da ABNT - Associação Brasileira de Norma técnica também contribuíram para uma melhor análise das exigências previstas pelas políticas públicas. Em relação à captação de dados documentais também foram enviados pela organização fotos da operação de descontaminação de lâmpadas fluorescentes para melhorar o entendimento do processo e visualização do maquinário estudado.

Concernente à pesquisa bibliográfica, foram coletadas informações de diversos autores através de aquisição de livros com foco ambiental e pesquisa de artigos em revistas de âmbito acadêmico-científico postados no Portal de periódicos da CAPES. Como instrumento de ligação entre a empresa e o pesquisador foi utilizado também à entrevista semiestruturada através do sistema eletrônico de e-mail para aquisição de respostas em relação às operações organizacionais concernente a título ambiental, realizadas pela Recilux. Os entrevistados foram os diretores corporativos responsáveis pelos processos técnicos e operacionais envoltos ao equipamento de descontaminação de lâmpadas fluorescentes - BULBOX.

\section{RESULTADOS E DISCUSSÃO}

Preza-se que consumidores finais de lâmpadas fluorescentes sendo eles fabricantes, distribuidores, empresas exportadoras como também importadores e consumidores finais primem pela responsabilidade socioambiental através de parceria com empresas do segmento de soluções ambientais que captam os resíduos de lâmpadas fluorescentes usadas utilizando como instrumentos equipamentos que oferecem operações de descontaminação de lâmpadas e reciclagem do material pesado (vidro, alumínio, cobre e latão), que permitem o seu reaproveitamento como nova fonte de matéria-prima no processo industrial.

\section{Mercúrio e seus impactos}

Diante de análises de conteúdo pode-se considerar que os efeitos danosos do mercúrio estão presentes em variadas atividades de caráter antrópica. Repercutem não só no descarte incorreto de lâmpadas fluorescentes como também em minerações (SIQUEIRA et al., 2012), nas inalações dos vapores de mercúrio metálico por profissionais de saúde bucal através da manipulação de amálgama dentária que tem um porcentual de mercúrio que varia de $43 \%$ a 53\% (CRAVO et al., 2008); (BEZERRA et al., 2013), e 
naturalmente nos danos ambientais provocados pelo descarte incorreto destes materiais odontológicos na biota aquática (BEZERRA et al., 2013).

Os estuários, ambientes aquáticos que conectam rio e mar, sofrem drasticamente com os impactos oriundos das contaminações por mercúrio $(\mathrm{Hg})$, pois atuam como agentes de locomoção de poluentes das grandes metrópoles para as áreas marítimas, contaminando diversas cadeias alimentares e é justamente por isso que a sociedade e, especificamente, as indústrias precisam efetivar ações de mitigação deste poluente orgânico persistente (POP) antes da manipulação ou descarte incorreto (LACERDA et al., 2008).

Os vapores de mercúrio $(\mathrm{Hg})$ existentes na atmosfera migram para a crosta da terra por vias pluviais, ocorrendo duas possibilidades de alteração químicas, sendo elas: volatilizar novamente junto à atmosfera ou desencadear a metilação de microrganismos originando o metilmercúrio (MMA, 2015). A possibilidade de volatilização do vapor de mercúrio $(\mathrm{Hg})$ nas lâmpadas fluorescentes que são descartadas de forma incorreta desencadeia grande possibilidade de contaminação dos rios, mares e solos, pois apesar do reduzido percentual deste metal por lâmpada o descarte de centenas delas pelas indústrias e pela sociedade em geral se torna um montante perigoso para o meio ambiente (SILVA, 2013).

Em 23 de março de 2011, a Comissão Nacional de Segurança Química (CONASQ; FUNDACENTRO, 2013) instituiu o Grupo de Trabalho sobre Mercúrio (GT-Mercúrio), que tem como objetivo discutir e propor estratégias, diretrizes, programas, planos e ações sobre o Instrumento Global Juridicamente Vinculante sobre o Mercúrio e encaminhar sugestões, no que for pertinente, para a participação brasileira na negociação do instrumento juridicamente vinculante sobre o mercúrio. O GT-Mercúrio foi atualizado em 2013, se reúne regularmente a cada 2 meses desde o dia 8 de junho de 2011, data da 1a reunião (MMA, 2015).

Algumas medidas estão sendo elaboradas para fomentar o controle e a redução do mercúrio em prol da saúde humana e do meio ambiente. Dentre essas diretrizes estipuladas pela convenção de Minamata é importante citar: "o controle de fontes e comércio de mercúrio, incluindo o banimento da mineração primária da substância, o controle e a redução de emissões de mercúrio ao meio ambiente e a eliminação ou redução do mercúrio em determinados produtos em processos industriais" (MMA, 2014).

\section{Sistema Bulbox ("Equipamento de descontaminação de lâmpadas")}

Este equipamento consiste em um moinho triturador de lâmpadas com estrutura constituída por um tambor de ferro, com sistema de sucção para aspiração e retenção do vapor de mercúrio. Os gases expelidos pelo componente passam por um filtro tecidual e um filtro de carvão ativo juntamente com o enxofre (S) amarelo. $\mathrm{O}$ enxofre $(\mathrm{S})$ se entrelaça com o mercúrio, desencadeando o sulfeto de mercúrio e posteriormente gerando uma composição insolúvel e de nula volatilidade (IBAMA, 2014).

O tambor de ferro tem capacidade para 200 litros, o que corresponde ao armazenamento de aproximadamente 1.000 mil lâmpadas descontaminadas, restando no fundo do tambor os resíduos de vidro e alumínio já caracterizados na classificação II (resíduos não perigosos) especificados pela ABNT NBR 10.004. Enfim, pode-se considerar que o tambor usado na destinação final de lâmpadas fluorescentes consiste em seu projeto arquitetônico "um sistema interno de aspiração e filtragem em três fases que se caracterizam da seguinte forma: sistema eletrônico de contagem de lâmpadas, controle de vida útil de filtros e desligamento 
automático" (BULBOX, 2016). São sistemas compostos por filtros, um para retenção dos detritos de vidro e pó fosfórico e o outro para a captação dos vapores de mercúrio, expelindo para o meio ambiente apenas o ar descontaminado. O equipamento funciona como um sistema de operações vinculadas a medidas de pressão ou medida de vácuo, possibilitando real segurança para o operador no tocante ao retorno residual e contaminação pelo vapor do mercúrio.

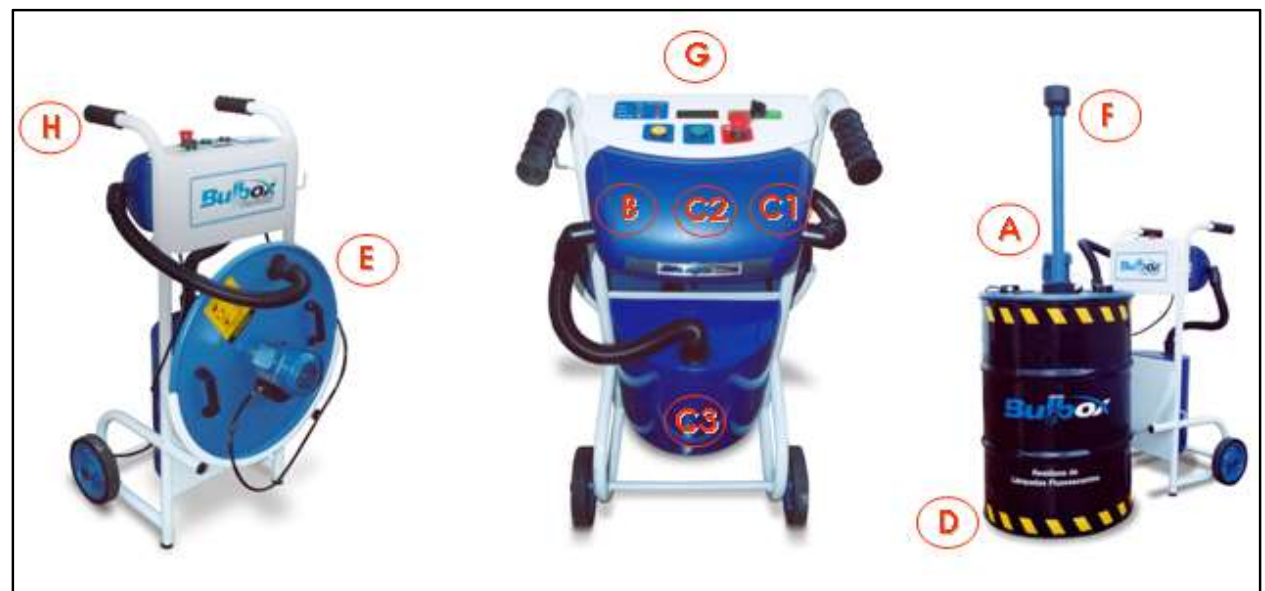

Figura 1: Sistema Bulbox de moagem de lâmpadas. Fonte: Bulbox (2016).

A) Motor Triturador 1/8 CV 110V 2A; B) Motor Aspirador 110/220; C) Filtros: C1) BAG: cada filtro é trocado após descontaminar 2.000 lâmpadas aproximadamente; (2) HEPA: cada filtro é trocado após descontaminar 12.000 lâmpadas aproximadamente; C3) CARVÃO ATIVADO: cada filtro é trocado após descontaminar 200.000 lâmpadas; D) Tambor Metálico 200L; E) Tampa Trituradora; F) Tubos de Aquisição; G) Painel de Controle: Luzes indicadoras; Display; Botão de Reset; Botão de Status; Botão de Acionamento; Botão de Emergência; H) Carrinho.
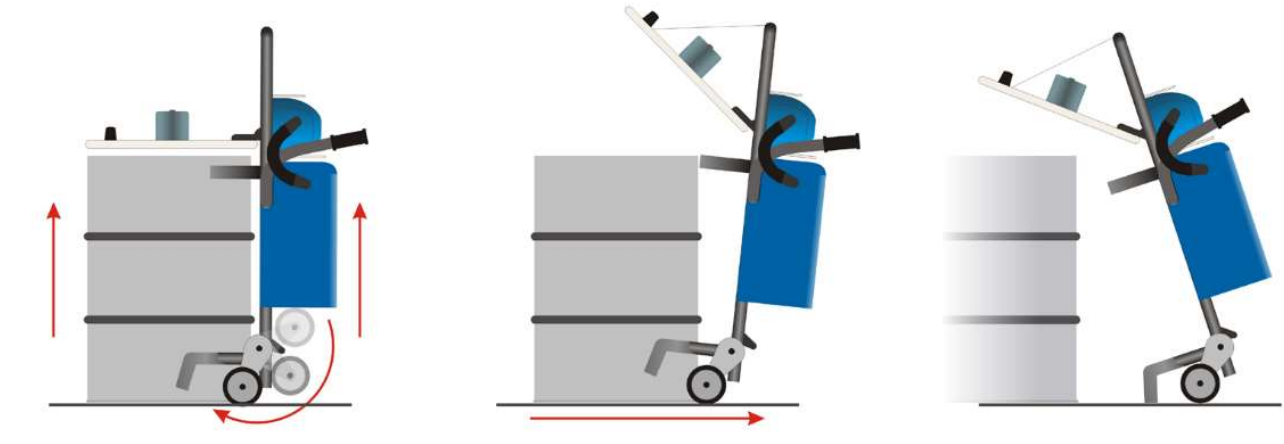

Figura 2. Sistema Bulbox ("Acoplamento de tambores). Fonte: (Bulbox, 2016)

A disseminação operacional do equipamento Bulbox é devida a sua praticidade: é um equipamento de fácil operacionalização e de tranquila mobilidade e com custos mais acessíveis referentes a outros tipos de tratamento de "LF".

As funcionalidades dos equipamentos (Bulbox) foram atestadas e aprovadas pelas funções bem exercidas de segurança e excelência no processo de filtragem e acomodação de partículas e elementos químicos resultantes da trituração a partir das exigências estipuladas pela NBR 10.004.

Segundo a empresa estudada, a quantidade de lâmpadas fluorescentes descontaminadas na região do Rio Grande do Sul e de Santa Catarina é, em média, 60.000 (sessenta mil) lâmpadas por mês. A empresa informou também o destino de tais resíduos: (a) O carvão ativado possui propriedades de adsorção, efetuando a transformação do vapor de mercúrio em estado sólido, possibilitando desta forma, o descartado em aterros industriais portadores de célula classe I, agindo de acordo com os processos de responsabilidade 
ambiental e cumprimento das exigências explicitadas nas políticas ambientais do segmento; (b) $O$ vidro centrifugado é direcionado para fábricas de cerâmicas e tintas; e (c) Os soquetes de metal são direcionados para empresas que reaproveitam esses resíduos recicláveis para fabricação de novos produtos de metal.

\section{Relatório Laboratorial das Lâmpadas Descontaminadas}

O relatório produzido pelo laboratório TECLAB - Tecnologia em Análises Ambientais apresentou a classificação do resíduo sólido: lâmpadas descaracterizadas que foram coletadas na empresa Recilux Reciclagem de Lâmpadas, explicitando os possíveis riscos potenciais ao meio ambiente e à saúde pública.

Informou também que foi realizada a classificação do resíduo de acordo com a Norma NBR/ABNT 10.004 - Resíduos Sólidos, 30/11/2004, sendo complementado pelas Normas NBR 10.005 - lixiviação de Resíduos - Procedimento; NBR 10.007 - Amostragem de Resíduos - Procedimento, NBR 10.006 Solubilização de Resíduos.

O ensaio de solubilização visa à adequação dos resíduos às normas da Organização Mundial de Saúde, complementadas pelo Padrão Brasileiro de Potabilidade da Água, Portaria ANVISA no 518, de 25 de março de 2004, atualmente substituída pela Portaria no 2.914, de 12 de dezembro de 2011. Os parâmetros analisados são, de acordo com o anexo G (NBR 10.004), padrões para ensaio de solubilização. Tais elementos, abaixo especificados nos quadros 1 e 1, foram encontrados na amostra das lâmpadas fluorescentes descontaminadas.

Quadro 1: Resultado para o estrato solubilizado.

\begin{tabular}{|c|c|c|c|c|c|c|}
\hline Parâmetro & Resultado & I.E & Unidade & L.Q. & V.M.P & Método \\
\hline Arsênio & $<0,01$ & $\pm 8,2 \%$ & $\mathrm{mg} \mathrm{As} . \mathrm{L}^{-1}$ & 0,01 & 0,01 & SM 3111 \\
\hline Bário & $<0,5$ & $\pm 6,0 \%$ & $\mathrm{mg} \mathrm{Ba} \cdot \mathrm{L}^{-1}$ & 0,5 & 0,7 & SM 3500-Ba \\
\hline Cádmio & $<0,001$ & $\pm 0,93 \%$ & $\mathrm{mg} \mathrm{Cd} . \mathrm{L}^{1}$ & 0,001 & 0,005 & SM 3500-Cd \\
\hline Chumbo & 0,1 & $\pm 2,5 \%$ & $\mathrm{mg} \mathrm{Pb} . \mathrm{L}^{-1}$ & 0,01 & 0,01 & SM $3500-\mathrm{Pb}$ \\
\hline Cromo & $<0,01$ & $\pm 1,0 \%$ & $\mathrm{mg} \mathrm{Cr} \cdot \mathrm{L}^{-1}$ & 0,01 & 0,05 & SM $3500-\mathrm{Cr}$ \\
\hline Mercúrio & $<0,001$ & $\pm 10 \%$ & $\mathrm{mg} \mathrm{Hg} \cdot \mathrm{L}^{1}$ & 0,001 & 0,001 & SM 3111 \\
\hline Prata & $<0,01$ & $\pm 0,93 \%$ & $\mathrm{mg} \mathrm{Ag} \cdot \mathrm{L}^{-1}$ & 0,01 & 0,05 & SM 3500-Ag \\
\hline Selênio & $<0,01$ & $\pm 6,4 \%$ & $\mathrm{mg} \mathrm{Se} . \mathrm{L}^{-1}$ & 0,01 & 0,01 & SM 3111 \\
\hline Manganês & 0,02 & $\pm 0,9 \%$ & $\mathrm{mg} \mathrm{Mn} \cdot \mathrm{L}^{-1}$ & 0,01 & 0,1 & SM 3500-Mn \\
\hline Ferro & $<0,3$ & $\pm 0,92 \%$ & $\mathrm{mg} \mathrm{Fe} . \mathrm{L}^{-1}$ & 0,3 & 0,3 & SM $3500-\mathrm{Fe}$ \\
\hline Cobre & $<0,05$ & $\pm 2,5 \%$ & $\mathrm{mgCu} \cdot \mathrm{L}^{-1}$ & 0,05 & 2,0 & SM 3500-Cu \\
\hline Alumínio & 0,14 & NE & mg Al. $L^{-1}$ & 0,05 & 0,2 & ISO 10566 E30 \\
\hline Sódio & 16,0 & $\pm 5,9 \%$ & $\mathrm{mg} \mathrm{Na} \cdot \mathrm{L}^{1}$ & 1,0 & 200 & SM $3500-\mathrm{Na} / \mathrm{B}$ \\
\hline Zinco & 0,01 & $\pm 1,0 \%$ & $\mathrm{mg} Z n \cdot L^{-1}$ & 0,01 & 5,0 & SM 3500-Zn \\
\hline Fluoretos & $<0,1$ & $\pm 4,9 \%$ & $m g F . L^{-1}$ & 0,1 & 1,5 & SM 4500-F/D \\
\hline Cianeto & $<0,005$ & $\pm 1,2 \%$ & $\mathrm{mg} \mathrm{CN} \cdot \mathrm{I}^{1}$ & 0,005 & 0,07 & $\mathrm{SM} 4500-\mathrm{CN} / \mathrm{E}$ \\
\hline Fenol & $<0,001$ & $\pm 0,38 \%$ & $\mathrm{mg} \mathrm{C}_{6} \mathrm{H}_{3} \mathrm{OH} \cdot \mathrm{L}^{-1}$ & 0,001 & 0,01 & SM 6420 \\
\hline Cloreto & 22,2 & $\pm 2,6 \%$ & $\mathrm{mg} \mathrm{Cr} \mathrm{L}^{-1}$ & 2,5 & 250 & SM 4500-CI/B \\
\hline
\end{tabular}

Fonte: Laudo Teclab, 2014.

De acordo com a Norma NBR 10.005 - Lixiviação de resíduos - o laboratório Teclab (2014) foi informado à empresa Recilux que os procedimentos e os ensaios ocorreram dentro dos critérios Standard Methods for the Examination of Water and Wastewater e U. S. Environmental Agency Protection - EPA (USEPA TEST METHODS FOR EVALUATING SOLID WASTE; Phisical/Chemical Methods SW 846). 
Quadro 2: Resultado para o estrato lixiviado.

\begin{tabular}{|c|c|c|c|c|c|c|}
\hline Parâmetro & Resultado & I.E & Unidade & L.Q. & V.M.P & Método \\
\hline Arsênio & $<0,1$ & $\pm 8,2 \%$ & $m g A s . L^{-1}$ & 0,1 & 1,0 & SM 3111 \\
\hline Bário & $<1,0$ & $\pm 6,0 \%$ & $\mathrm{mg} \mathrm{Ba} \cdot \mathrm{L}^{-1}$ & 1,0 & 70 & SM 3500-Ba \\
\hline Cádmio & $<0,01$ & $\pm 0,93 \%$ & $\mathrm{mg} \mathrm{Cd} . \mathrm{L}^{1}$ & 0,01 & 0,5 & SM $3500-\mathrm{Cd}$ \\
\hline Chumbo & 0,15 & $\pm 2,5 \%$ & $\mathrm{mg} \mathrm{Pb} \cdot \mathrm{L}^{-1}$ & 0,1 & 1,0 & $\mathrm{SM} 3500-\mathrm{Pb}$ \\
\hline Cromo & $<0,1$ & $\pm 1,0 \%$ & $\mathrm{mg} \mathrm{Cr} \cdot \mathrm{L}^{-1}$ & 0,1 & 5,0 & $\mathrm{SM} 3500-\mathrm{Cr}$ \\
\hline Cromo Hexavalente & $<0,1$ & $\pm 1,0 \%$ & 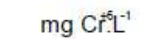 & 0,1 & $\ldots$ & $\mathrm{SM} 3500-\mathrm{Ct}^{6}$ \\
\hline Prata & $<0,01$ & $\pm 0,93 \%$ & $\mathrm{mg} \mathrm{Ag} \cdot \mathrm{L}^{-1}$ & 0,01 & 5,0 & SM 3500-Ag \\
\hline Mercúrio & $<0,01$ & $\pm 10 \%$ & $\mathrm{mg} \mathrm{Hg} \cdot \mathrm{L}^{-1}$ & 0,01 & 0,1 & SM 3111 \\
\hline Selênio & $<0,01$ & $\pm 6,4 \%$ & $\mathrm{mg} \mathrm{Se} \cdot \mathrm{L}^{-1}$ & 0,01 & 1,0 & SM 3111 \\
\hline Fluoretos & $<0,1$ & $\pm 4,9 \%$ & $\mathrm{mg} F \cdot \mathrm{L}^{-1}$ & 0,1 & 150 & SM 4500-F/D \\
\hline Cianeto & $<0,005$ & $\pm 1,2 \%$ & $\mathrm{mg} \mathrm{CN}: L^{-1}$ & 0,005 & $\ldots$ & $\mathrm{SM} 4500-\mathrm{CN} / \mathrm{E}$ \\
\hline Óleos e Graxas Totais & $<5,0$ & $\pm 1,2 \%$ & $\mathrm{mg} \cdot \mathrm{L}^{-1}$ & 5,0 & $\ldots$ & SM $2540 / C$ \\
\hline Fenol & $<0,01$ & $\pm 0,38 \%$ & $\mathrm{mg} \mathrm{C}_{3} \mathrm{H}_{5} \mathrm{OH}^{-1} \mathrm{~L}^{-1}$ & 0,01 & - & SM 6420 \\
\hline Benzeno & $<0,01$ & $\pm 0,74 \%$ & $\mathrm{mg} \cdot \mathrm{L}^{-1}$ & 0,01 & 0,5 & EPA 3890 \\
\hline Benzo(a)pireno & $<0,01$ & $\pm 8,1 \%$ & $\mathrm{mg} \cdot \mathrm{L}^{-1}$ & 0,01 & 0,07 & EPA 8100 \\
\hline Cloreto de Vinila & $<0,01$ & $\pm 3,0 \%$ & $\mathrm{mg} \cdot \mathrm{L}^{-1}$ & 0,01 & 0,5 & EPA 624 \\
\hline Clorobenzeno & $<0,01$ & $\pm 3,0 \%$ & $m g \cdot L^{-1}$ & 0,01 & 100 & EPA 624 \\
\hline Clorofórmio & $<0,01$ & $\pm 3,0 \%$ & $m g \cdot L^{-1}$ & 0,01 & 6,0 & EPA 624 \\
\hline
\end{tabular}

Fonte: Laudo Teclab, 2014.

No relatório do laboratório está explicitado que o resíduo não apresentou nenhum indício de inflamabilidade, corrosividade, reatividade, patogenicidade e toxicidade para o meio ambiente e para a saúde pública. Segundo o relatório de ensaio $n^{\circ} 23.349$ expedido pelo laboratório TECLAB, a amostra não apresenta toxicidade e não possui potencial patogênico, conforme BA 23.349 não caracterizando como D004 (NBR 10004:2004). O Extrato Lixiviado atendeu os parâmetros do Anexo F (NBR 10004:2004). Não foi evidenciado metal significativo na Massa Bruta, classificando-a, portanto, como resíduo classe II - não perigoso, concluindo desta forma a real eficácia do equipamento "Bulbox" no processo de descontaminação de lâmpadas fluorescentes.

\section{CONSIDERAÇÕES FINAIS}

Considera-se indispensável o diálogo referente aos sérios riscos que o mercúrio pode desencadear na sociedade. Esse metal pode ser altamente toxico gerando efeitos devastadores no organismo humano e por ser um poluente orgânico persistente (POP) chega a animais e seres humanos de forma muito mais potencializada. Foram relatados estudos desenvolvidos por especialistas em contaminações por parte do mercúrio evidenciando de forma plausível os impactos globais sobre a saúde do homem e do meio ambiente (PNEUMA, 2013).

Justamente por esses fatores de nocividade do mercúrio que a Lei 12.305 de 02 de agosto de 2010, que instituiu a PNRS - Política Nacional de Resíduos Sólidos estabeleceu a obrigatoriedade de logística reversa para as lâmpadas fluorescentes por parte dos geradores ou daqueles que são corresponsáveis por sua destinação final.

Diante das imperiosas exigências governamentais para a saúde e bem-estar do meio ambiente, cerca de 140 países, inclusive o Brasil, promoveram no mês de outubro de 2013 em Kumamoto no Japão - a 
Convenção de Minamata - para diálogo sobre redução, controle e eliminação do mercúrio em operações industriais e artesanais em âmbito mundial. Parafraseando o tratado, mensura-se que até os anos de 2020, será erradicada a manufatura, exportação e importação de produtos que tenha em sua constituição mercúrio (MMA, 2013). Dentre os produtos com mercúrio proibidos pós-data limite "phase out", com algumas ressalvas, e com necessária aprovação do Congresso Nacional, estão às baterias, comutadores e interruptores, lâmpadas fluorescentes compactas, lineares, cosméticos, pesticidas, biocidas, antissépticos tropicais, equipamentos de medições não eletrônicos (SÃO PAULO, 2013).

Enquanto as datas e acordos propostos pelas convenções político-econômicas não se concretizam, diversas empresas se solidificam no mercado de soluções ambientais para aplicação de descontaminação de lâmpadas fluorescentes.

De acordo com os dados mensurados no relatório 23.349 expedido pelo laboratório TECLAB no tocante a materiais descontaminados pela empresa Recilux, observou-se a efetividade nas relações harmônicas entre discurso e prática dentro dos processos de descontaminação de lâmpadas fluorescentes. Através da análise de amostras de materiais sólidos que foram descontaminados foi observada a inexistência de toxidade como também a ausência de potencial patogênico. Tais amostras alcançaram com sucesso os valores requeridos em lei no tocante à permissividade de quantidade máxima de mercúrio para saudáveis relações entre homem e meio ambiente, obtemperando com isso a consideração de que a empresa estudada - Recilux - desenvolve com eficiência e eficácia a descontaminação de lâmpadas fluorescentes utilizando como ferramenta o equipamento - Bulbox - que utiliza o método de moagem simples.

No tocante as limitações do estudo podem-se considerar que a análise físico-química se bitolou apenas a um laboratório para detalhar a existência de compostos perigosos pós-processo de descontaminação da "LF". É interessante também considerar que na atualidade existem diversos fabricantes do equipamento triturador de lâmpadas que utiliza o método de moagem simples e que não se pode afirmar o efetivo sucesso sem a observância das atividades de descontaminação e das comprovações de análises laboratoriais catalogando a eficácia operacional.

Enquanto recomendação para futuros estudos indica-se à observância de outras formas de descontaminações de lâmpadas fluorescentes não informadas nesta pesquisa, como por exemplo: a operação de moagem com tratamento térmico, moagem com tratamento químico, tratamento por sopro e tratamento via solidificação/encapsulamento. Outro critério de análise futura é a avaliação de risco dos agentes que operacionalizam o equipamento e respectivos critérios de exigências em relação aos equipamentos de proteção individual - EPI's utilizados.

E por fim, conclui-se que as ações realizadas pela organização estudada detentora do maquinário triturador de lâmpadas fluorescentes estimula a mitigação de nocividade do mercúrio ao meio ambiente, considerando factível a eficiência e eficácia do equipamento Bulbox - triturador e compactador de lâmpadas fluorescentes nos processos de descontaminação das lâmpadas que contêm mercúrio (Hg). 


\section{REFERÊNCIAS}

ALMEIDA, F. O bom negócio da sustentabilidade. São Paulo: Nova Fronteira, 2002.

APLIQUIM. Tecnologia Ambiental. Porto Alegre: Apliquim Brasil Recicle, 2015.

AIR CYCLE CORPORATION. THE BULB EATER LAMP CRUSHER. BROADVIEW: ACC, 2002.

BEZERRA, J. J.; MELO, A. M.; SILVA, E. V. Contaminação do meio ambiente através do mercúrio decorrente dos consultórios odontológico. Natural Resources, v.3, n.2, 2013. DOI: http://10.6008/ESS2237-9290.2013.002.0034

BOENING, D. W.. Ecological effects, transport, and fate of mercury: a general review. PubMed Us Nation Library of Medicine Nation Institutes of Health, Chemosphere, v.40, p.1335-1351, 2000

BRASIL. Constituição da República Federativa do Brasil. 1988.

BULBOX. Sistema de Descartes de Lâmpadas Fluorescentes Queimadas. Rio Grande do Sul: Recilux, 2015.

CALDERONI, S.. Os bilhões perdidos no lixo. 3 ed. São Paulo: Humanitas, 1999.

CAPRA, F.. A teia da vida. 13 ed. São Paulo: Cultrix, 2006.

CETESB. Companhia Ambiental do Estado de São Paulo. Ficha de informação toxicológica do Acetaldeído. São Paulo: ABIQUIM, 2012.

CETEM. Centro de Tecnologia Mineral. 0 caso de Minamata. Rio de Janeiro: MCT, 2006.

CONCEIÇÃO, M.. Os empresários do lixo: um paradoxo da modernidade: análise interdisciplinar das cooperativas de reciclagem do lixo. 2 ed. São Paulo: Átomo, 2005.

FUNDACENTRO. Fundação Jorge Duprat Figueiredo de Segurança e Medicina do Trabalho. A CONASQ e o Processo de Negociação Intergovernamental para Elaboração da Convenção de Minamata. São Paulo: CONASQ, 2013.

CRAVO, M.; VIEIRA, R.; GONÇALO, M.; FIGUEIREDO, A intoxicação aguda por mercúrio aplicado na pele. Revista Medicina Cutánea Ibero-Latino-Americana, v.36, n.6, p.296298, 2008.

DESLAURIERS J. P.. Recherche qualitative: guide pratique. Québec (Ca): McGrawHill, Éditeurs, 1991.

DURÃO JR, W.A.; WINDMOOLLER, C. C.. A questão do mercúrio em lâmpadas fluorescentes. Química Nova na Escola, n.28, p. 15-19, 2008.

FARIAS, L. A.; FAVARO, D. I. T.. Mercúrio total em cabelo de crianças de uma população costeira, Cananéia, São Paulo, Brasil. Cad. Saúde Pública, v.24, n.10, p.2249-2256, 2008.

FEPAM. Fundação Estadual de Proteção Ambiental. Rio Grande do Sul, 2015.
FERREIRA, L. G. R.. Redação Científica: como entender e escrever com facilidade. São Paulo: Atlas, 2011.

FISPQ. Ficha de Informações de Produto Químico. Mercúrio vivo. Santa Catarina: Quimidrol, 2009.

FIRJAN. Federação das Indústrias do Rio de Janeiro. Guia para coleta seletiva de pilhas e baterias. Rio de Janeiro: FIRJAN, 2000.

FUNDACENTRO. Fundação Jorge Duprat Figueiredo de Segurança e Medicina do Trabalho. Seminário de Atualização sobre o Mercúrio. São Paulo: MTE, 2013.

GLINA, D. M .R.; SATUT, B. T. G.; ANDRADE, E. M. O. A. C.. A exposição ocupacional ao mercúrio metálico no módulo odontológico de uma unidade básica de saúde localizada na cidade de São Paulo. Cad. Saúde Pública, Rio de Janeiro, v.13, n.2, p.1-11, 1997. DOI: http://dx.doi.org/10.1590/S0102311X1997000200015

GUSMÃO, A. C. F.; DE MARTINI, L. C.. Gestão ambiental na indústria. Rio de Janeiro: SMS Digital, 2009.

GUTIÉRREZ, Francisco. Ecopedagogia e cidadania planetária. São Paulo: Cortez, 2013.

IBAMA. Instituto Brasileiro do Meio Ambiente e dos Recursos Naturais Renováveis. Mercúrio metálico. Brasília: MMA, 2015

LACERDA, L. D.; MALM, O.. Contaminação por mercúrio em ecossistemas aquáticos: uma análise das áreas críticas. Revista Instituto de Estudos Avançados, São Paulo, v.22, n.63, 171-190, 2008.

LIMA, E. R. Z.; COLON, J. C.; SOUZA, M. T.. Alterações auditivas em trabalhadores expostos a mercúrio. Revista CEFAC, São Paulo, v.11, n.1, p.62-67, 2009.

MALHOTRA, N. K. Pesquisa de marketing: uma orientação aplicada. 3 ed. Porto Alegre: Bookman, 2001.

MEDEIROS, João Bosco. Redação científica: a prática de fichamento, resumo, resenhas. 12 ed. São Paulo: Atlas, 2014.

MIMURA, A. M. S.; SALES, J. R. C.; PINHEIRO, P. C.. Atividades Experimentais Simples Envolvendo Adsorção Sobre Carvão. Química Nova na Escola, São Paulo, v.32, n.1, p. 53-56, 2010.

MMA. Ministério do Meio Ambiente. Brasil e 140 países assinam acordo para eliminação gradual do mercúrio. Brasília: Esplanada dos ministérios, 2013.

MMA. Ministério do Meio Ambiente. Mercúrio. Brasília: Esplanada dos ministérios, 2014.

MMA. Ministério do Meio Ambiente. Brasil sedia encontra de ratificação da convenção sobre mercúrio. Brasília: Esplanada dos ministérios, 2014.

NEBEL, B. J.; WRIGHT, R. T.. Environmental Science. 7 ed. New Jersey: Prentice Hall, 2000. 
PGIRPBL. Plano de Gerenciamento de Resíduos de Pilhas, Baterias e Lâmpadas. Minas Gerais: FEAM, 2009.

PAWLOWSKI, L.. Effect of mercury and lead on the total environment. Environmental Protection Engineering, Lublin, v.37, n.1, p.105-117, 2011.

PERNAMBUCO. Decreto $n^{\circ} \mathbf{2 3 . 9 4 1}$, de 11 de janeiro de 2002. Dispõe sobre a Política Estadual de Resíduos Sólidos, e dá outras providências. Pernambuco, 2002.

PERNAMBUCO. Lei Estadual $\mathbf{n}^{\circ} \mathbf{1 4 . 2 3 6}$, de 13 de dezembro de 2010. Dispõe sobre a Política Estadual de Resíduos Sólidos, e dá outras providências. Pernambuco, 2006.

PROCEL. Programa Nacional de Conservação de Energia Elétrica. Manual de Iluminação Eficiente. Rio de Janeiro: CEPEL, 2002.

RATTNER, H.. Liderança para uma Sociedade Sustentável. São Paulo: Nobel, 1999.

RECILUX. Descontaminação e Reciclagem de Lâmpadas Fluorescentes. Rio Grande do Sul: Recilux, 2015.

RIBEIRO, D. V.; MORELLI, M. R.. Resíduos sólidos: problema ou oportunidade?. Rio de Janeiro: Interciência, 2009.

RIO GRANDE DO SUL. Lei Estadual $\mathbf{n}^{\circ} \mathbf{1 1 . 1 8 7}$ de $\mathbf{0 7}$ de julho de 1998. Dispõe sobre o descarte e destinação final de pilhas que contenham mercúrio metálico, lâmpadas fluorescentes, baterias de telefone celular e demais artefatos que contenham metais pesados no Estado do Rio Grande do Sul. Porto Alegre, 1998.

RODRIGUES, A. P.; CARVALHEIRA, R. G.; CESAR, R. G.; BIDONE, E. D.; CASTILHOS, Z. C.; ALMOSNY, N. R..

Bioacumulação de mercúrio em quatro espécies de peixes tropicais oriundos de ecossistemas estuarinos do Estado do Rio de Janeiro, Brasil. Anuário do Instituto de Geociências, Rio de Janeiro, v.33 n.1, p.54-62, 2010.

SANCHES, E. S. S.. Logística Reversa de Pós-Consumo do Setor de Lâmpadas Fluorescentes. In: CONGRESSO NACIONAL DE ENGENHARIA MECÂNICA, 5. Anais. Salvador, 2008.

SÃO PAULO. Lei Estadual n $\mathbf{1 2 . 3 0 0}$ de $\mathbf{1 6}$ de março de 2006. Dispõe sobre a Política Estadual de Resíduos Sólidos e define princípios e diretrizes. São Paulo, 2006.

SIQUEIRA, G. W.; APRILE, F. M.. Distribuição de mercúrio total em sedimentos da Plataforma Continental Amazônica Brasil. Revista Acta Amazônica, Manaus, v.42, n.2, p.259268, 2012.

SILVA, R.. Impactos ambientais associados à logística reversa de lâmpadas fluorescentes. Revista de Saúde, Meio Ambiente e Sustentabilidade, São Paulo, v.8, n.1, p.42-69, 2013.

TOMAZELLI, A. C.. Estudo comparativo das concentrações de cádmio, chumbo e mercúrio em seis bacias hidrográficas do Estado de São Paulo. Tese (Doutorado em Ciências) Universidade de São Paulo, Ribeirão Preto, 2003.
UNEP. United Nations Environment Program. Chemicals: Global Mercury Assessment. Geneva, 2002.

PNEUMA. Programa das Nações Unidas para o Meio Ambiente. Projetos vai pesquisar dados sobre mercúrio no Brasil. Brasília, 2013.

WHO. World Health Organization. Environamental Health Criteria 118 - Inoranic Mercury. International Programme on Chemical Safety. Geneva, 1991.

WHO. World Health Organization. Elemental mercury and inorganic mercury compounds: human health aspects. Geneva, 2003.

WOLFF, E. H; CONCEIÇÃO, S. V.. Resíduos sólidos: a reciclagem de pilhas e baterias no Brasil. Minas Gerais: Abrepro, 2015. 